\title{
Examining Relationships between the Cognitive Aspect of College Students' Attitudes toward Physical Education and Their Social Skills in Physical Education Classes
}

\author{
Jiandong Ding, Yoshio Sugiyama \\ Faculty of Human-Environment Studies, Kyushu University, Fukuoka, Japan \\ Email:djd19810716@yahoo.co.jp
}

How to cite this paper: Ding, J. D., \& Sugiyama, Y. (2018). Examining Relationships between the Cognitive Aspect of College Students' Attitudes toward Physical Education and Their Social Skills in Physical Education Classes. Advances in Physical Education, 8, 20-30

https://doi.org/10.4236/ape.2018.81003

Received: November 10, 2017

Accepted: January 30, 2018

Published: February 2, 2018

Copyright $\odot 2018$ by authors and Scientific Research Publishing Inc. This work is licensed under the Creative Commons Attribution International License (CC BY 4.0).

http://creativecommons.org/licenses/by/4.0/

\begin{abstract}
This study aimed to examine the relationships between the cognitive aspect of college students' attitudes toward physical education (PE) and their social skills in PE classes. A sample of 573 first-year students (269 male and $304 \mathrm{fe}-$ male, mean age $=17.6$ years) in China was investigated in terms of their social behaviors in current PE classes and evaluations of their high school PE. Correlation and multiple regression analyses were conducted to determine the relationships between the two variables. Results of correlation analyses indicated a significant connection between total attitudes and nonverbal skills in all students. Results of multiple regression analyses revealed that three aspects of attitude that toward self-actualization and social development, PE teacher, and PE teaching were related to nonverbal skills in both male and female students. This study explored variable factors of PE that contributed to students' social development and provided implications according to those factors in PE.
\end{abstract}

\section{Keywords}

Attitudes, College Students, Verbal Skills, Nonverbal Skills, Physical Education Classes, Development

\section{Introduction}

In recent years, development of social skills has been emphasized among other goals of PE at school, such as improvement of physical fitness and sports skills, acquirement of knowledge in PE and sport, and development of instrumental personal dispositions. Research interested in the contribution of PE to students' 
social development goes back many years (Weiss \& Bredemeier, 1990). PE provides students with opportunities to communicate with others and take different social roles to develop particular social skills (Svoboda, 1994). However, social skills development does not appear to occur automatically with participation in PE. Conversely, it should be achieved through teaching programs carefully designed by researchers and educators and taught by trained teachers who are competent in performing them. To date, a growing number of instructional models and programs (e.g., cooperative learning \& sport education) have been developed and commonly implemented in PE (Metzler, 2011). However, studies exploring the mechanism of how students' social skills can be developed are limited. There may be certain factors that influence students' social development in PE. The key issue in educational research is to identify these factors to understand how PE promotes students' social skills. It is only through this knowledge that we can create a valuable learning environment and suitably implement programs in the environment to enhance students' social skills.

It has historically been a goal of PE programs to develop students' positive attitudes toward PE (Siedentop, 2000) as it has been demonstrated that there are positive relationships between students' attitudes and learning outcomes ( $\mathrm{Pa}$ paioannou, 1994; Solmon, 2003), and students' attitudes could affect their future participation in physical activity (Carlson, 1995; Ennis, 1996; Silverman \& Subramaniam, 1999; Subramaniam \& Silverman, 2000; Zeng, Hipscher, \& Leung, 2011). Attitude has been viewed by researchers as a single-, two-, or multicomponent construct (Subramaniam \& Silverman, 2000). The single-component view restricts the use of the term to the affective component. This view of attitude could result in measuring only part of an attitude (Oppenheim, 1992). The two-component view is that attitude involves the cognitive and affective aspects (Gonza'lez, 1992; Mohsin, 1990; Oppenheim, 1992). According to this framework, the cognitive component accounts for the beliefs about the characteristics of $\mathrm{PE}$, and the affective component measures the degree of emotional attraction or feeling towards PE. Students' beliefs about PE affect their feelings toward the subject matter, which may subsequently determine the formation of attitude (Ajzen, 1993; Biddle \& Mutrie, 2001; Eagly \& Chaiken, 1993; Gonza'lez, 1992; Hagger et al., 2002). The multi-component construct of attitude includes cognition, affect, and conation (Ajzen, 1993; Reddy \& LaBarbera, 1985). Supporters of the multi-component construct (Hilgard, 1980; Reddy \& LaBarbera, 1985) proposed that beliefs about the characteristics of an attitude object and feelings toward the attitude object impact behavior. However, the efficacy of this view has been doubted by researchers who suggested a lack of consistent relationship between overt behavior and the measured attitude (McGuire, 1989; Seeman, 1993). Some researchers have pointed out the important role played by behavioral intentions in linking attitude to behavior and proposed that, without the mediation of intention, the relationship between attitude and behavior is weak (Biddle \& Mutrie, 2001; Hagger et al., 2002). 
While researchers have put much emphasis on the influence of attitude on student's academic outcomes and future participation in physical activities, as we know, little attention has been paid to the contribution of attitudes to social development. Sollerhed et al. (2005) noted a correlation between positive attitudes toward PE and the feeling of a strong social bond among young people; Sugiyama (2012) proposed that students' positive attitudes toward PE may influence the improvement of certain types of nonverbal skills. Research on attitudes toward PE often employs instruments that measure attitude using the two-component model (Subramaniam \& Silverman, 2000). Investigating students' attitudes can reveal valuable information about what they think, feel, and know about PE (Graham, 1995). However, according to the limited studies focused on students' social development, the influences of attitudes were determined from the affective aspect. No study has explored the relationships between students' beliefs about characteristics of PE and social skills in the classes. Investigating the cognitive aspect of attitudes may provide insight into $\mathrm{PE}$ from the students' perspectives and reflect the quality of materials provided by $\mathrm{PE}$ from several aspects. Examining students' attitudes toward PE from the cognitive aspect can help us explore the factors that contribute to students' social development in the learning. Therefore, the purpose of this study was to explore factors contributing to college students' social skills in PE through examining the relationships between the cognitive aspect of attitudes toward PE and social skills in PE classes.

\section{Methods}

\subsection{Instruments}

\subsubsection{Item of Social Skills Inventory (11-SSI)}

The Social Skills Inventory (SSI) (Riggio, 1986, 1989) is a standardized and representative instrument created to examine certain key dimensions of adults' social skills in daily lives. It measures social skills in six subscales: social expressivity, social sensitivity, social control, emotional expressivity, emotional sensitivity, and emotional control. Social expressivity, social sensitivity, and social control are subscales that determine people's verbal skills, while emotional expressivity, emotional sensitivity, and emotional control examine people's nonverbal skills. As social behaviors can be learned in one domain (e.g., PE classes) and generalized or transferred to other fields (e.g., school, family, and community) (Maureen, Nicole, \& Lindsay, 2014), there may be differences between social skills students acquire in a PE setting and those they use in their daily lives (Sugiyama et al., 2010). Based on Riggio's SSI, Ding and Sugiyama (2016) developed the 11-SSI to assess Chinese college students' social skills in PE classes. The items in the scale were selected from the SSI and revised according to the contexts of PE and social culture of China. The 11-SSI assesses students' basic communication skills in PE classes. The scale has 11 items distributed across two subscales: verbal skills (five items) and nonverbal skills (six items). For example, the items "It 
is difficult for me to speak when facing all class members" and "I feel very uncomfortable when being criticized" determine students' social expressivity and social sensitivity, which reflect their verbal skills in PE classes; while the items "I am good at express myself by eyes" and "When I feel sad or depressed, others can hardly detect my feelings" examine students' emotional expressivity and emotional control, which are aspects of their nonverbal skills in PE classes. Each item must be answered on a five-point Likert scale including two negative and three positive agreement responses ranging from "not at all like me" to "exactly like me." There is an identical score corresponding to each item so that the scores on the subscales range from 5 to 30 . The scale has demonstrated content validity and an internal consistency reliability coefficient of 0.92 with a sample of Chinese college students (Ding \& Sugiyama, 2016).

\subsubsection{Students' Attitudes toward Physical Education (SATPE)}

The SATPE (Li, Chen, \& Baker, 2014) is an inter-correlated model of college students' attitudes toward PE. The instrument consists of 26 items distributed across five subscales: physical fitness (four items), self-actualization and social development (five items), PE curriculum (five items), PE teachers (six items), and PE teaching (six items). Items of each subscale describe the characteristics and/or attributes of PE toward the subscale domains. For example, the items "PE improved my levels of health and fitness" and "PE developed my motor skills" address the functions of PE in improving physical fitness; the items "My PE teacher is friendly" and "My PE teacher is highly professional and good at PE sports" are descriptions of PE teachers' character and teaching competence. Students are asked to indicate how strongly they agree with each description or comment using a six-point Likert scale including two negative and four positive agreement responses ranging from "strongly disagree" to "strongly agree." There is an identical score corresponding to each item so that the scores on the subscales range from 4 to 36 . The model has demonstrated content validity and an average mean of internal consistency reliability coefficient of 0.76 for the five subscales with a sample of Chinese college students (Li, Chen, \& Baker, 2014). Therefore, the SATPE is a reliable and valid instrument that assesses the cognitive aspect of college students' attitudes toward PE.

\subsection{Participants and Procedures}

We carried out a survey in October, 2015. A sample of 573 first-year students (269 male, 304 female, mean age $=17.6$ years) who had been studying at two universities in two cities (i.e., Dalian \& Sanya) in China for only one month were investigated. Students at the university in Dalian are 140 male and 159 female; students at the university in Sanya are 129 male and 145 female. All of the students were investigated using a questionnaire containing items of the SATPE and 11-SSI. First, we called the chairs of the PE departments of the two universities to acquire approval for the investigation. Then, after we had received permissions 
for the investigations as well as agreements of assistance from the two chairs, we posted questionnaires to the two PE departments. The two chairs called for teachers to administer the questionnaires. Each administration was carried out before a lesson in a quiet place (e.g., classroom or a play-ground far from other class groups) without distractions. The questionnaires were collected and returned by post after administration.

\subsection{Data Analysis}

We performed correlation analyses to examine whether there were relationships between the cognitive aspect of students' attitudes toward PE and their social skills in PE classes. We performed multiple regression analyses to assess the influences of the cognitive aspect of students' attitudes toward PE on their social skills in PE classes. Data were analyzed using SPSS 22.0 for Windows.

\section{Results}

\subsection{Results of Correlation Analyses}

To determine whether there were relationships between the cognitive aspect of college students' attitudes toward PE and their social skills in PE classes, we performed correlation analyses separately on male $(n=269)$ and female samples $(n=$ 304). Correlation coefficients were separately calculated for total attitude scores and scores of social skills variables (i.e., verbal and nonverbal skills). Results (Table 1) indicated that total attitudes had a significant correlation with nonverbal skills in both male $(r=0.279, p<0.01)$ and female students $(r=0.125, p<$ 0.05 ). However, no significant correlation was found between total attitudes and verbal skills in either male or female students.

\subsection{Influences of Attitudes on Social Skills}

To determine whether the cognitive aspect of students' attitudes toward PE influences college students' social skills in PE classes, we performed multiple regression analyses separately on male $(n=269)$ and female samples $(n=304)$. First, collinearity diagnostics indicated that the collinearity for variables of attitude in each sample was weak (VIF $=1.356-1.798$ ). Then, five aspects of attitude (i.e., physical fitness, self-actualization and social development, PE curriculum, PE teachers, and PE teaching) were entered to regress on each sample's verbal and nonverbal skills. Results (Table 2) showed that the $R^{2}$ of the regression

Table 1. Total attitudes in relation to verbal and nonverbal skills in male and female samples.

\begin{tabular}{ccc}
\hline & \multicolumn{2}{c}{ Total attitudes } \\
\cline { 2 - 3 } & Male $(n=269)$ & Female $(n=304)$ \\
\hline Verbal skills & 0.034 & 0.068 \\
Nonverbal skills & $0.279^{* *}$ & $0.125^{\star}$ \\
\hline
\end{tabular}

${ }^{*} p<0.05,{ }^{* *} p<0.01$. 
Table 2. Regression models of attitudes in relation to verbal and nonverbal skills in male and female samples.

\begin{tabular}{|c|c|c|c|c|c|c|c|c|}
\hline & \multicolumn{4}{|c|}{ Verbal skills ${ }^{\mathrm{a}}$} & \multicolumn{3}{|c|}{ Nonverbal skills ${ }^{\mathrm{a}}$} & \multirow[b]{2}{*}{$R^{2}$} \\
\hline & $\beta$ & $S E$ & $t$ & $R^{2}$ & $\beta$ & $S E$ & $t$ & \\
\hline \multicolumn{9}{|l|}{ Male $(n=269)$} \\
\hline Physical fitness & 0.005 & 0.168 & 0.039 & & 0.040 & 0.156 & 0.319 & \\
\hline $\begin{array}{c}\text { self-actualization } \\
\text { and social } \\
\text { development }\end{array}$ & -0.008 & 0.163 & -0.054 & & 0.261 & 0.089 & $2.337^{\star}$ & \\
\hline PE curriculum & 0.066 & 0.354 & 0.540 & & 0.099 & 0.329 & 0.883 & \\
\hline PE teacher & 0.110 & 0.216 & 0.851 & & 0.256 & 0.132 & $2.163^{\star}$ & \\
\hline \multirow[t]{2}{*}{ PE teaching } & -0.002 & 0.131 & -0.017 & & 0.368 & 0.122 & $3.063^{\star *}$ & \\
\hline & & & & 0.010 & & & & $0.172^{* * *}$ \\
\hline \multicolumn{9}{|l|}{ Female $(n=304)$} \\
\hline Physical fitness & 0.053 & 0.097 & 0.621 & & -0.095 & 0.099 & -1.179 & \\
\hline $\begin{array}{c}\text { self-actualization } \\
\text { and social } \\
\text { development }\end{array}$ & -0.055 & 0.093 & -0.596 & & 0.306 & 0.091 & $3.382^{* * *}$ & \\
\hline PE curriculum & 0.148 & 0.269 & 1.692 & & 0.079 & 0.274 & 0.924 & \\
\hline PE teacher & 0.064 & 0.150 & 0.698 & & 0.241 & 0.120 & $2.019^{\star}$ & \\
\hline \multirow[t]{2}{*}{ PE teaching } & -0.105 & 0.087 & -1.113 & & 0.220 & 0.151 & $1.997^{\dagger}$ & \\
\hline & & & & 0.020 & & & & $0.103^{* *}$ \\
\hline
\end{tabular}

${ }^{\mathrm{a}}$ Dependent variable. ${ }^{*} p<0.05,{ }^{* *} p<0.01,{ }^{* * *} p<0.001,{ }^{\dagger} p=0.061$.

equation in which attitudes were regressed on nonverbal skills reached the significant level in both male $\left(R^{2}=0.172, p<0.001\right)$ and female samples $\left(R^{2}=\right.$ $0.103, p<0.01)$. It indicated that attitudes had a strong influence on nonverbal skills in all students. Of the five aspects of attitude, self-actualization and social development was found to have a positive and significant influence on both male and female students' nonverbal skills $(\beta=0.261, t=2.337, p<0.05 ; \beta=0.306, t=$ $3.382, p<0.001)$; the PE teachers aspect was found to have a positive and significant influence on both male and female students' nonverbal skills ( $\beta=0.256, t=$ 2.163, $p<0.05 ; \beta=0.241, t=2.019, p<0.05)$; PE teaching was found to have a positive and significant influence on male students' nonverbal skills $(\beta=0.368$, $t=3.063, p<0.01$ ), and a positive influence that neared but did not reach the significant level on female students' nonverbal skills $(\beta=0.220, t=1.997, p=$ 0.061). However, no significant influences of physical fitness and PE curriculum were found on either male or female students' social skills.

\section{Discussion}

Attitude is particularly important in the area of PE. The promotion of positive attitudes is one key component that impacts students' learning (Solmon, 2003). The purpose of this study was to explore the relationships between the cognitive 
aspect of college students' attitudes toward PE and their social skills in PE classes. First, through correlation analyses, we found positive and significant connections between attitudes and nonverbal skills. The findings can be the basis for determining the influences of attitudes on social skills. Then, by performing multiple regression analyses, we found that certain aspects of attitude may affect nonverbal skills in both male and female students. The cognitive aspect of students' attitudes toward PE is their beliefs about the characters of PE, and it can reflect the features from students' views of the PE they had experienced before. Therefore, through examining the relationships between those attitudes and students' social skills, we can determine the factors that can facilitate students' social development in PE. The finding of this study that attitudes have positive influence on nonverbal skills may correspond to the results of other studies that revealed developmental tendency (Ding \& Sugiyama, 2016) and interventional feasibility (Ding \& Sugiyama, 2017; Sugiyama, 2012) of college students' nonverbal skills in PE classes. PE provides important contexts in which students' socials skill levels can be influenced. According to the results, students' attitude that PE can facilitate their self-actualization and social development has a positive influence on their nonverbal skills. This indicated that students who had positive experiences of self-actualization (e.g., gaining confidence in participation) and social development (e.g., demonstrating personal and social responsibility) showed high levels of nonverbal skills. PE has the potential to provide students with positive sport experiences by bringing students together in a shared interest, providing a sense of belonging to a team, offering opportunities for developing valued competencies and capabilities, and developing social networks and community cohesion (Bailey, 2005). Students' social skills, especially nonverbal skills, can be developed by the influence of the positive sport experiences (Ding \& Sugiyama, 2017). However, for students to acquire positive sport experiences in PE, constructions of careful planning, effective teaching, and meaningful learning are required (Carpenter, 2010), and teachers may play the crucial role for the realizations of these constructions. In this study, students who had high evaluation of the teachers showed high levels of nonverbal skills; students' attitudes toward PE teachers were found to be related to their nonverbal skills. This means that teachers themselves can influence students' social development. Besides parents, teachers are most frequently identified by youth as having the strongest influence on their beliefs and actions (Smokowski, Reynolds, \& Bezruczko, 1999; Winfield, 1991). Students' social development is an ongoing process that often requires the support of teachers and peers with whom they have close interactions during learning in classes. A teacher's positive social behaviors in the classes could be directly learned by students and copied in and out of the classes when interacting with others. Besides, teachers' behaviors could affect students' enjoyment (Cai, 1998; Cecchini et al., 2001; Hashim, Grove, \& Whipp, 2008) and willingness for self-disclosure (Anita, Karen, \& Mark, 1977) in PE. The positive sport experiences that involve enjoyment 
and/or self-disclosure contributed to students' social skills in PE classes (Ding \& Sugiyama, 2017). Teachers should realize their great potential in influencing students' behaviors and take care of their actions when teaching PE. While students are the center of PE, teachers make all the aspects of PE focus on students' learning outcomes, such as physical and psychosocial development. Therefore, it is not only teachers' behaviors when interacting with students that affect students' social skills; their actions in organizing the PE process, such as making syllabi, choosing teaching strategies, and managing classes, determine other factors that can influence students' social development. The actions of teachers largely determine whether or not students can receive the positive influences of PE. Therefore, among other factors in PE, PE teachers may be the key factor that contributes to students' social development. PE teaching is associated with variables what $\mathrm{PE}$ provides during the teaching process, such as teaching content, learning environment, and teaching strategies. The current study revealed that students' perceptions of PE teaching positively influence their nonverbal skills in both male and female students, although the influence in female students closely approached but did not reach the significant level. Therefore, the function of PE teaching on students' social development should be emphasized by educators to promote students' social skills. However, it must through careful organizing, such as choosing appropriate programs, creating positive learning environment, and using suitable teaching strategies, that the function of this factor be realized. There have been several programs or models developed for using in PE. Each of them contributed to certain aspect(s) of students' social development. Educators should use these programs or models, or those created by them, to develop students' social skills in PE classes. Students desire to be successful or to spend their time without academic pressure in PE class. If students were provided with a comfortable and confident learning environment, their enjoyment of PE would be increased, and their learning would be impacted (Ravizza \& Stratton, 2007; Subramaniam \& Silverman, 2007). Consequently, their social skills would be improved. Teachers should use various teaching strategies in implementing programs and creating positive learning environments. Games are one typical strategy widely used by teachers at all levels of school. However, only games that contain enough skills-related physical activities, student-based designed challenges, and social interactions can work as a quality teaching strategy. In this study, the cognitive aspect of students' attitudes was used as a tool to examine the variable factors of PE that contributed to students' social skills development in the PE classes. The findings can help researchers and educators in this field more clearly understand the mechanism of how PE contributes to students' social development and can provide researchers and educators with suggestions on intervention program development, curriculum modification, and teacher professional training. However, this study was limited by using only quantitative approach to assess students' attitudes and social skills. In future studies, qualitative approach should be used to understand the relationships between the two variables. 


\section{References}

Ajzen, I. (1993). Attitude Theory and the Attitude-Behavior Relation. In D. Krebs, \& P. Schmidt (Eds.), New Directions in Attitude Measurement (pp. 41-57). New York: de Gruyter.

Anita, E. W., Karen, S. G., \& Mark, J. N. (1977).The Impact of Teacher Behavior, Teacher Sex, and Student Sex upon Student Self-Disclosure. Contemporary Educational Psychology, 2, 124-132. https://doi.org/10.1016/0361-476X(77)90015-7

Bailey, R. (2005). Evaluating the Relationship between Physical Education, Sport and Social Inclusion. Educational Review, 57, 71-90.

https://doi.org/10.1080/0013191042000274196

Biddle, S. H. J., \& Mutrie, N. (2001). Psychology of Physical Activity: Determinants, Well-Being and Interventions. New York, NY: Routledge.

Cai, S. X. (1998). Student Enjoyment of Physical Education Class in Three Teaching Style Environments. Education, 118, 412-421.

Carlson, T. B. (1995). We Hate Gym: Student Alienation from Physical Education. Journal of Teaching in Physical Education, 14, 467-471.

https://doi.org/10.1123/jtpe.14.4.467

Carpenter, E. J. (2010). The Tactical Games Model Sport Experience-An Examination of Student Motivation and Game Performance during an Ultimate Frisbee Unit. Doctor Dissertation, University of Massachusetts.

Cecchini, J. A., Gonzalez, C., Carmona, A. M., Arruza, J., Escarti, A., \& Balague, G. (2001). The Influence of Physical Education Teacher on Intrinsic Motivation, Self-Confidence, Anxiety, and Pre- and Post-Competition Mood States. European Journal of Sport Science, 1, 1-11. https://doi.org/10.1080/17461390100071407

Ding, J., \& Sugiyama, Y. (2016). Development of a Scale to Assess Chinese College Students' Social Skills in Physical Education Classes. Journal of Heal Science, 38, 11-19.

Ding, J., \& Sugiyama, Y. (2017). Exploring Influences of Sport Experiences on Social Skills in Physical Education Classes in College Students. Advances in Physical Education, 7, 248-259. https://doi.org/10.4236/ape.2017.73020

Eagly, A. H., \& Chaiken, S. (1993). The Psychology of Attitudes. Orlando, FL: Harcourt Brace Jovanovich.

Ennis, C. D. (1996). Students' Experiences in Sport-Based Physical Education: (More Than) Apologies Are Necessary. Quest, 48, 453-456. https://doi.org/10.1080/00336297.1996.10484211

Gonza'lez, V. E. (1992). On Human Attitudes: Root Metaphors in Theoretical Conceptions. Gothenburg: VasastadensBokbinderi AB.

Graham, G. (1995). Physical Education through Students' Eyes and in Students' Voices: Implications for Teachers and Researchers. Journal of Teaching in Physical Education, 14, 478-482. https://doi.org/10.1123/jtpe.14.4.478

Hagger, M. S., Chatzisarantis, N. L., \& Biddle, J. H. (2002). A Meta-Analytic Review of the Theories of Reasoned Action and Planned Behavior in Physical Activity: Predictive Validity and the Contribution of Additional Variables. Journal of Sport and Exercise Psychology, 24, 3-32. https://doi.org/10.1123/jsep.24.1.3

Hashim, H. A., Grove, J. R., \& Whipp, P. (2008). Testing a Model of Physical Education Enjoyment and Physical Activity among High School Students. Journal of Research in Health, Physical Education, Recreation, Sport \& Dance, 3, 95-99.

Hilgard, E. R. (1980). The Trilogy of Mind: Cognition, Affection, and Conation. Journal 
of the History of the Behavioral Sciences, 16, 107-117. https://doi.org/10.1002/1520-6696(198004)16:2<107::AID-JHBS2300160202>3.0.CO;2-Y

Li, F., Chen, J., \& Baker, M. (2014). University Students' Attitudes toward Physical Education Teaching. Journal of Teaching in Physical Education, 33, 186-212. https://doi.org/10.1123/jtpe.2012-0187

Maureen, R. W., Nicole, D. B., \& Lindsay, E. K. (2014). Assessing Impact of Physical Activity-Based Youth Development Programs: Validation of the Life Skills Transfer Survey (LSTS). Research Quarterly for Exercise and Sport, 85, 263-278. https://doi.org/10.1080/02701367.2014.931558

McGuire, W. J. (1989). The Structure of Individual Attitudes and Attitude System. In A. R. Pratkanis, S. J. Breckler, \& A. G. Greenwald (Eds.), The Third Ohio State University Vol. on Attitudes and Persuasion. Attitude Structure and Function (pp. 37-69). Hillsdale, NJ: Lawrence Erlbaum Associates.

Metzler, M. W. (2011). Instructional Models for Physical Education (3rd ed.). Scottsdale, AZ: Holcomb Hathaway.

Mohsin, S. M. (1990). Attitude: Concept, Formation and Change. New Delhi: Wiley.

Oppenheim, A. N. (1992). Questionnaire Design, Interviewing and Attitude Measurement. New York, NY: St. Martin's Press.

Papaioannou, A. (1994). Development of a Questionnaire to Measure Achievement Orientations in Physical Education. Research Quarterly for Exercise and Sport, 65, 11-20. https://doi.org/10.1080/02701367.1994.10762203

Ravizza, D. M., \& Stratton, R. K. (2007). Students' Perceptions of Physical Education Teachers' Caring. Research Quarterly for Exercise and Sport, 78, 70-72.

Reddy, S., \& LaBarbera, P. (1985). Hierarchical Models of Attitude. Multivariate Behavioral Research, 20, 451-471. https://doi.org/10.1207/s15327906mbr2004_6

Riggio, R. E. (1986). Assessment of Basic Social Skills. Journal of Personality and Social Psychology, 51, 649-660. https://doi.org/10.1037/0022-3514.51.3.649

Riggio, R. E. (1989). Manual of the Social Skills Inventory. Palo Alto, CA: Consulting Psychologists Press.

Seeman, M. (1993). A Historical Perspective on Attitude Research. In D. Krebs, \& P. Schmidt (Eds.), New Directions in Attitude Measurement (pp. 3-20). New York, NY: de Gruyter.

Siedentop, D., \& Deborah, T. (2000). Developing Teaching Skills in Physical Education (4th ed.). Mountain View, CA: Mayfield.

Silverman, S., \& Subramaniam, P. R. (1999). Student Attitude toward Physical Education and Physical Activity: A Review of Measurement Issues and Outcomes. Journal of Teaching in Physical Education, 19, 97-125. https://doi.org/10.1123/jtpe.19.1.97

Smokowski, P. R., Reynolds, A. J., \& Bezruczko, N. (1999). Resilience and Protective Factors in Adolescence: An Autobiographical Perspective from Disadvantaged Youth. Journal of School Psychology, 37, 425-448. https://doi.org/10.1016/S0022-4405(99)00028-X

Sollerhed, A. C., Ejlertsson, G., \& Apitzsch, E. (2005). Predictors of Strong Sense of Coherence and Positive Attitudes to Physical Education in Adolescents. Scandinavian Journal of Public Health, 33, 334-342. https://doi.org/10.1080/14034940510005833

Solmon, M. A. (2003). Student Issues in Physical Education Classes: Attitudes, Cognition, and Motivation. In S. J. Silverman, \& C. D. Ennis (Eds.), Student Learning in Physical Education: Applying Research to Enhance Instruction (pp. 147-163). Champaign, IL: Human Kinetics. 
Subramaniam, P. R., \& Silverman, S. (2000). Validation of Scores from an Instrument Assessing Student Attitude toward Physical Education. Measurement in Physical Education and Exercise Science, 4, 29-43. https://doi.org/10.1207/S15327841Mpee0401_4

Subramaniam, P. R., \& Silverman, S. (2007). Middle School Students' Attitudes toward Physical Education. Teaching and Teacher Education, 23, 602-611. https://doi.org/10.1016/j.tate.2007.02.003

Sugiyama, Y. (2012). Process of Acquisition, Improvement, and Development of Nonverbal Skills through Physical Education (Grant No. 21500564). Research Report, JSPS KAKENHI.

Sugiyama, Y., Shibukura, T., Nishida, T., Ito, T., Sasaki, B., \& Isogai, H. (2010). Development of Scales for Psychosocial Skills in Physical Education and Life Skills. Journal of Health Science, 32, 77-84.

Svoboda, B. (1994). Sport and Physical Activity as a Socialization Environment: Scientific Review Part 1. Strasbourg: Council of Europe.

Weiss, M., \& Bredemeier, B. (1990). Moral Development in Sport. In K. Pandolf, \& J. Hollowszy (Eds.), Exercise and Sport Sciences Reviews (pp. 331-374). Baltimore, MD: Williams and Wilkins. https://doi.org/10.1249/00003677-199001000-00015

Winfield, L. F. (1991). Resilience, Schooling, and Development in African-American Youth: A Conceptual Framework. Education and Urban Society, 24, 5-14. https://doi.org/10.1177/0013124591024001001

Zeng, H. Z., Hipscher, M., \& Leung, R. W. (2011). Attitudes of High School Students toward Physical Education and Their Sport Activity Preferences. Journal of Social Sciences, 7, 529-537. https://doi.org/10.3844/jssp.2011.529.537 